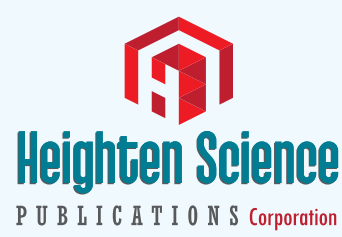

ISSN

2640-2866

\title{
Assessing the Neurocognitive function effects of ketamine in Cardiac Surgical patients
}

\author{
Demet Dogan Erol*
}

Associate Professor, MD, Department of Anesthesiology and Reanimation. University of Health Sciences. Diskapi Education and Research Hospital. Ankara, Turkey

\begin{abstract}
*Address for Correspondence: Demet Dogan Erol, Associate Professor, MD, Department of Anesthesiology and Reanimation. University of Health Sciences. Diskapi Education and Research Hospital, 1467 Cad. No: 6/19 Dilay Sitesi, 06520 Cukurambar, Ankara, Turkey, Tel: 0090542 4306936; Email:

demetdoganerol@mynet.com
\end{abstract}

Submitted: 30 September 2018

Approved: 22 October 2018

Published: 23 October 2018

Copyright: @ 2018 Erol DD. This is an open access article distributed under the Creative Commons Attribution License, which permits unrestricted use, distribution, and reproduction in any medium, provided the original work is properly cited

Keywords: Cardiac surgical procedures; Cardiopulmonary bypass; General anesthesia; Ketamine; Propofol; Neuroprotective agents

Check for updates

\section{Abstract}

Background: Despite remarkable progress in surgical, cardiopulmonary bypass (CPB) and anesthetic tecniques, neurocognitive damage still remains an important cause of postoperative morbidity in cardiac surgery. The aetiology of neurocognitive damage is likely to be multifocal; including macro and microemboli, cerebral hypoperfusion, inflammation and nonpulsatile flow. N-methyl-D-asparticAcid (NMDA) receptors play an important role during neurocognitive damage. Ketamine is a non-competitive antagonist to the phencyclidine site of NMDA receptor for glutamate and directly suppresses proinflammatory cytokine production. The aim of the present study was to evaluate whether ketamine has neuroprotective effects during open-heart surgery through the use of neurocognitive tests.

Methods: We considered all patients aged between 58-76 years who were referred to a single cardiothoracic surgical team for elective, primary coronary revascularization. Patients were excluded from the study for the following reasons: a history of neurological, psychiatric, gastrointestinal, hepatic, renal, hematologic and clotting systems disorder and repeat procedures. Undergoing CPB were randomized 2 groups: Group1 (ketamine) $(n=25)$ or Group2 (propofol) $(n=$ Patients 25$)$ In the propofol group, anesthesia was induced with $3 \mathrm{mg} / \mathrm{kg}$ propofol, $1 \mu \mathrm{g} / \mathrm{kg}$ remifentanyl, $0.1 \mathrm{mg} / \mathrm{kg}$ vecuronium. Remifentanyl $0.5-1 \mu \mathrm{g} /$ $\mathrm{kg} / \mathrm{min}$ was infused intravenously throughout the whole procedure. In the ketamine group, anesthesia was induced with $1-2 \mathrm{mg} / \mathrm{kg}$ propofol, $1-2 \mathrm{mg}$ ketamin, $0.1 \mathrm{mg} / \mathrm{kg}$ vecuronium. Ketamin $1 \mathrm{mg} / \mathrm{kg} / \mathrm{hour}$ was infused intravenously. Pressors, inotropic agents and antiarrhythmics were used as needed. The MiniMental State Examination(MMSE) was administered the day before surgery and three days later. The change in scores for MMSE was calculated for each patient and all the group. The results were compared statistically with paired simple t-test.

Results: The mean age, CBP duration, lowest temperature was not statistically significant (Table1). Peroperative and postoperative blood pressures and pulse rates showed differences between groups. There were no preoperative differences between the groups on any of the mean MMSE score (Table2). The ECG monitoring revealed that most patients remained in sinus rhythm, with no difference between groups.

Conclusions: We could not demonstrate that intraoperatively administered ketamine resulted in greater neuroprotective effects compared with propofol. Ketamine in combination with propofol during cardiac surgery is associated with a stable hemodynamic profile. Propofol may reduce the delivery of microemboli to the cerebral circulation by decreasing the cerebral blood flow. Propofol has a direct neuroprotective effect in vitro, although Roach et al. could not demonstrate a protective effect of propofol during open-heart surgery. Propofol enhances the antiinflammatory response to surgery by several mechanisms. This might have masked a neuroprotective effect of ketamine because propofol was administered in both groups in our study.

\section{Introduction}

Despite remarkable progress in surgical, cardiopulmonary bypass (CPB) and anesthetic tecniques, neurocognitive damage stil remains an important cause of postoperative morbidity in cardiac surgery [1,2]. The aetiology of neurocognitive damage is likely to be multifocal; including macro and micro emboli, cerebral hypoperfusion, inflammation and nonpulsatile flow [3,4]. Ketamine reduces postischemic neuronal cell loss in the cortex, directly suppresses proinflammatory cytokine production and 
improves neurological outcome after cerebral ischemia in rats [5]. Demonstrated that $\mathrm{S}(+)$-ketamine protects neurons after glutamate damage and a small beneficial effect on cognitive performance with ketamine, also a N-methyl-D-aspartic acid (NMDA)-receptor antagonist, after cardiac surgery [6].

We planned to assessing the neurocognitive function effects of ketamine to 50 patients undergoing coronary artery bypass surgery (CABS), using repeated Mini Mental Test (MMSE) as indicative of cognitive dysfunction.

\section{Subject and Method}

The study was conducted in accordance with the provisions of the Declaration of Helsinki (amended in 1989) and with the approval of Kocatepe University, Faculty of Medicine Ethical Review Committee.

We considered all patients aged between 58 and 76 years who were referred to a single cardiothoracic surgical team for elective, primary coronary revascularization. Patients were excluded from the study for the following reasons: a history of neurological (including previous transient ischemic attacks, stroke, and seizures), psychiatric, gastrointestinal, hepatic, renal or hematologic and clotting systems disorder; evidence within the previous 2 years of drug abuse (prescribed or no prescribed) or regular use of antiepileptics, antidepressants and emergency cases and repeat procedures.

Patients undergoing cardiopulmonary bypass (CPB) were randomized 2 groups: Group1 (ketamine) ( $\mathrm{n}=25)$ or Group2 (propofol) $(\mathrm{n}=25)$ in a double-blind manner at the time of induction of general anesthesia. In the propofol group, anesthesia was induced with $3 \mathrm{mg} / \mathrm{kg}$ propofol, $1 \mu \mathrm{g} / \mathrm{kg}$ remifentanyl, $0.1 \mathrm{mg} / \mathrm{kg}$ vecuronium. Remifentanyl $0.5-1 \mu \mathrm{g} / \mathrm{kg} / \mathrm{min}$ was infused intravenously throughout the whole procedure. In the ketamine group, anesthesia was induced with $1-2 \mathrm{mg} / \mathrm{kg}$ propofol, $1-2 \mathrm{mg}$ ketamin, $0.1 \mathrm{mg} / \mathrm{kg}$ vecuronium. Ketamin $1 \mathrm{mg} / \mathrm{kg} /$ hour was infused intravenously. Pressors, inotropic agents and antiarrhythmics were used as needed during induction. There was no difference between the groups in terms of intraoperative blood losses were not significant. There were no instances of significant hypotension, hypertension, hypothermia or systemic hypoxemia.

Standard physiological monitoring electrocardiogram (ECG), arterial pressure, central venous pressure, nasopharyngeal temperature, fraction of inspired oxygen $\left(\mathrm{FiO}_{2}\right)$, end-tidal carbon dioxide concentration $\left(\mathrm{ETCO}_{2}\right)$, airway pressure, peripherial $\mathrm{O}_{2}$ saturation $\left(\mathrm{PerSaO}_{2}\right)$, and urine output was used throughout the procedure. CPB was established with a flatbed membrane oxygenator with a cardiotomy reservoir/filter and 2 or 3 low-pressure cardiotomy suckers. Moderate hypothermia $\left(32^{\circ} \mathrm{C}\right)$ was used during CPB. Pump flow was adjusted to achieve $2.4 \mathrm{~L} \cdot \mathrm{min}^{-1} \cdot \mathrm{m}$ at $37^{\circ} \mathrm{C}$ and $1.8 \mathrm{~L} \cdot \mathrm{min}^{-1}$ - $\mathrm{m}$ at $32^{\circ} \mathrm{C}$. Mean arterial pressure (MAP) was maintained between 50 and $60 \mathrm{~mm} \mathrm{Hg}$. In the postoperative course, all patients were electively ventilated for variable periods depending on several factors, at least until the morning of the day following surgery.

Cognitive function was measured using Mini-Mental State Examination (MMSE) on day before surgery and three days later (Scale A).

Statistical evaluations were made using SPSS for Windows (SPSS 11.5 for Windows). The change in scores for MMSE (preoperative and postoperative) was calculated for each patient and for all the group and the results were compared statistically with paired simple t-test.

\section{Results}

Seventy consenting patients were randomized from a consecutive series over a 2-year period before randomization, 20 patients were excluded on the basis of abnormal laboratory baseline values, withdrawal of consent, the discovery of a history 


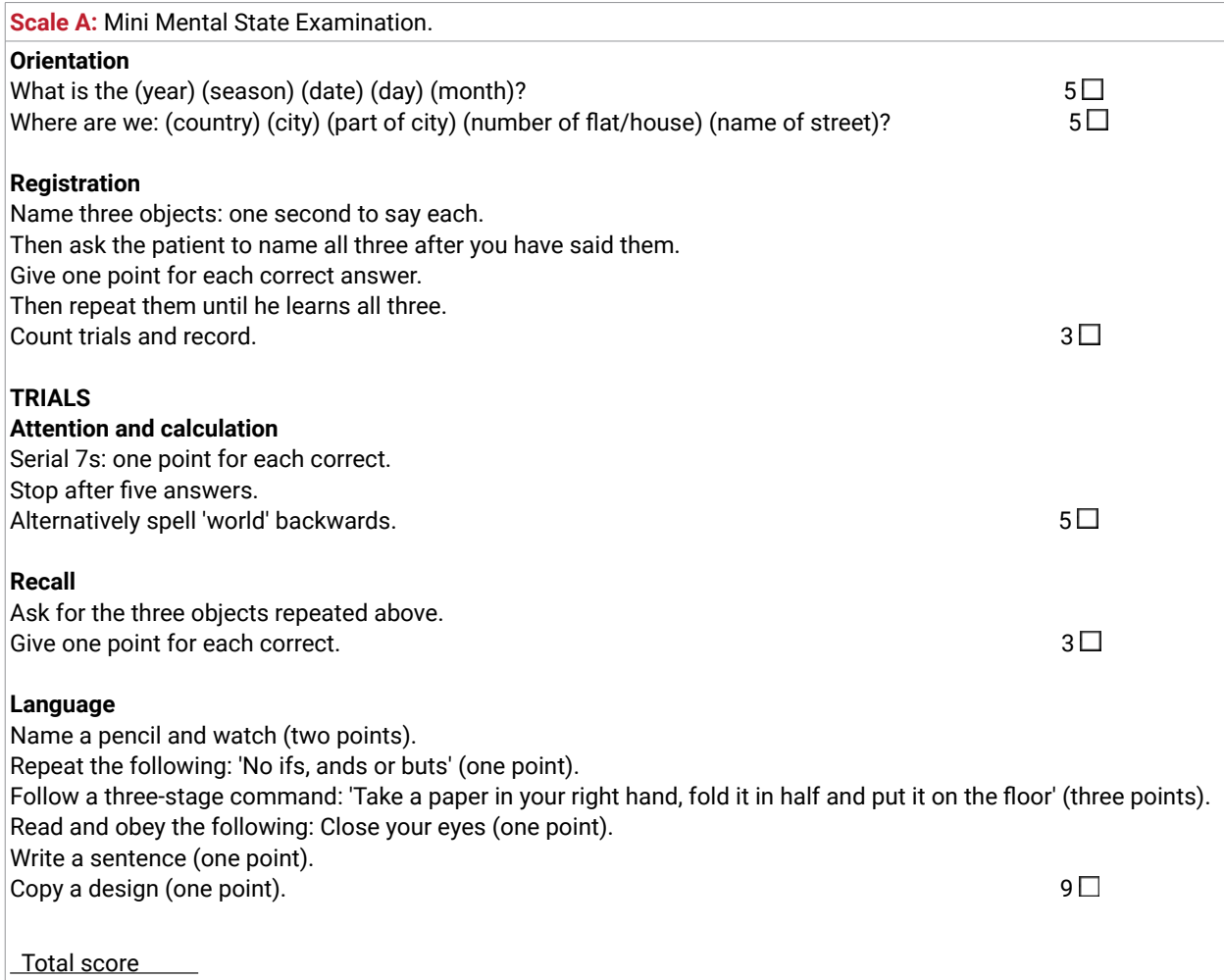

of disallowed medication or systemic disorder, or delay or difficulty in completing preoperative asessments. 50 patients completed both tests. The two groups were comparable with respect to demographics and MMSE Scores.

The mean age, CBP duration, lowest temperature was not statistically significant (Table 1). Biochemical, hematologic, and clotting screen data both before and after surgery showed no differences. Perioperative and postoperative blood pressures and pulse rates showed differences between groups. Perioperative nasopharyngeal temperatures and pump flow rates showed no differences between groups. The ECG monitoring revealed that most patients remained in sinus rhythm, again with no difference between groups.

In analyzing the preoperative and postoperative scores for MMSE, Paired Samples Statistics were used. There were no preoperative differences between the groups on any of the mean MMSE score (Table 2) (Figure 1).

\section{Discussion}

Neurologic complications following CPB may be as high as 40\% [1,7]. The etiology of cognitive dysfunction after cardiac surgery is multifactorial and includes cerebral micro embolization, global cerebral hypo perfusion, systemic and cerebral inflammation, cerebral temperature perturbations, cerebral edema, and possible blood-brain barrier dysfunction, all superimposed on genetic differences in patients that may make them more susceptible to injury or unable to repair from injury once it has occurred $[3,4,8]$.

In the early 1950s experimental models of CPB showed promise, but initial human trials were disappointing. In just 60 years CPB has progressed from a riskily laboratory experiment to an event occurring many times daily through the world. Unfortunately, in this time, the reported incidence of clinical neuropsychiatric dysfunction after CPB varies considerably. Despite numerous technical advances, neurologic and neuropsychiatric dysfunction continues to be significant and undeniable risks of cardiac surgery [9]. The most commonly used form of cerebral protection during CPB is hypotermia. Another approach to improving cerebral outcome during cardiac surgery is to use drugs or techniques that might protect the brain [10]. Although controversial, 


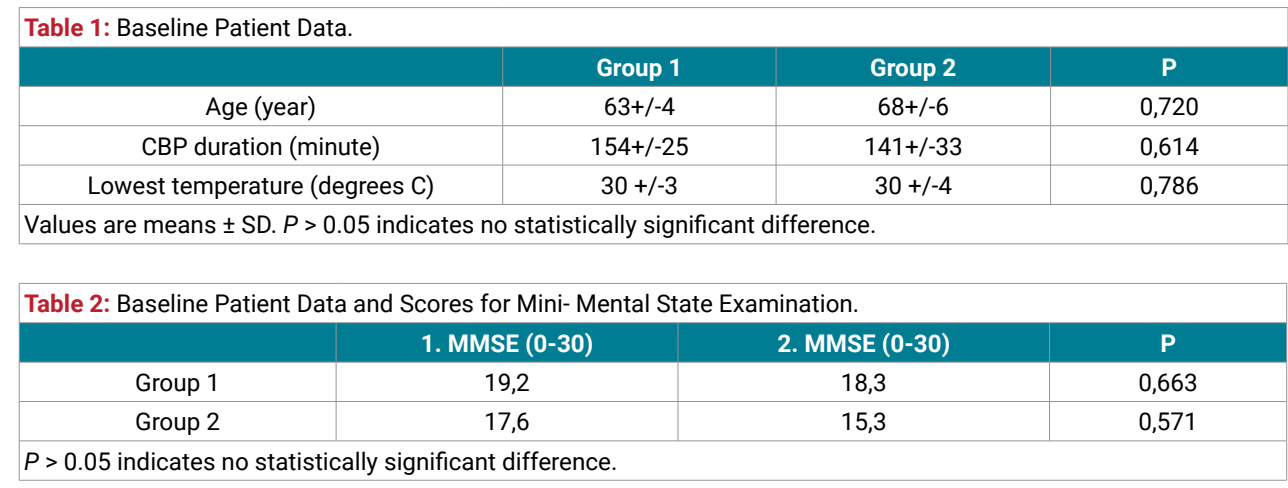

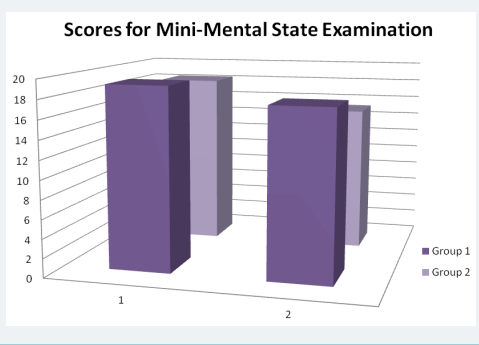

Figure 1: Mini Mental State Scores.

prophylactic thiopental infusions (completely suppressing electroencephalographic activity) immediately prior to and during intracardiac procedures have been reported to decrease the incidence and severity of neurologic deficits. Propofol may reduce the delivery of microemboli to the cerebral circulation by decreasing the cerebral blood flow [11]. Propofol has a direct neuroprotective effect in vitro, although Roach et al., could not demonstrate a protective effect of propofol during open-heart surgery [12]. Propofol enhances the antiinflammatory response to surgery by several mechanisms. Studies suggest that magnesium may also be beneficial [13]. The role of calcium channel blockers (nimodipine and nicardipine) and N-methyl-D-aspartate (NMDA) antagonists (ketamine) remains largely investigational [14]. Although controversial, calcium channel blockers and N-methyl-D-aspartate (NMDA) antagonists have been reported to decrease the incidence and severity of neurologic deficits [15]. It had been found to inhibit convulsions induced by NMDA and reduce cerebral damage in animal models of focal ischemia, properties shared with dizocilpine (MK-801). Its modest NMDA antagonism is apparently due to an active desglycinated metabolite $[16,17]$. Maximal neuroprotection occurred in the animal studies when the drug was administered before the onset of cerebral ischemia.

The effect of glutamate in this context highlights the possibility of further reducing the morbidity of CABS. The use of membrane rather than bubble oxygenators and other changes in surgical anesthetic and perfusion practice, including the choice of filters, has already been associated with a decline in the incidence of neuropsychological sequelae.

The MMSE is a good instrument for assessing cognitive function, but takes up to 10 minutes and cannot fit easily into a standard consultation (Scale A) [18,19]. Weissrock $\mathrm{S}$, et al., suggested the MMSE could be systematically integrated to the pre and postoperative screening [20]. In this study, cognitive function was measured using Mini-Mental State Examination.

We could not demonstrate that intraoperatively administered ketamine resulted in greater neuroprotective effects. This might have masked a neuroprotective effect of ketamine because propofol was administered in both groups in our study. Propofol may reduce the delivery of microemboli to the cerebral circulation by decreasing the cerebral blood flow. Propofol enhances the antiinflammatory response to surgery by several mechanisms. 
Ketamine in combination with propofol during cardiac surgery is associated with a stable hemodynamic profile.

\section{References}

1. Lombard FW, Mathew JP. Neurocognitive dysfunction following cardiac surgery. Sem Cardiothorac Vasc Anesth 2010; 14: 102-110. Ref.: https://goo.gl/4R41sv

2. Arrowsmith J, Grocott $H$, Reves J, Newman MF. Central nervous system complications of cardiac surgery. Br J Anaesth 2000; 84: 378-393. Ref.: https://goo.gl/4WJr1t

3. Pugsley $W$, Klinger $L$, Paschalis $C$, Treasure $T$, Harrison $M$, et al. The impact of microemboli in cardiopulmonary bypass on neuropsychological functioning. Stroke 1994; 25: 1393-1399. Ref.: https://goo.gl/Ya8K6Z

4. Smith QR. Transport of glutamate and other amino acids at the blood-brain barrier. J Nutr 2000; 130 (4- I): 1016-1022. Ref.:https://goo.gl/eCC29Q

5. Kawasaki T, Ogata M, Kawasaki C, Ogata J, Inoue Y, et al. Ketamine suppresses proinflammatory cytokine production in human whole blood in vitro. Anesth Analg. 1999; 89: 665-669. Ref.: https://goo.gl/3tmdxB

6. Nagels W, Demeyere R, Hemelrijck JV, Vandenbussche E, Gijbels K, et al. Evaluation of the Neuroprotective Effects of S(+)-Ketamine During Open-Heart Surgery. Anesth Analg. 2004; 98: 15951603. Ref.: https://goo.gl/cqVBqe

7. Hindman BJ, Todd MM. Improving Neurologic Outcome after Cardiac Surgery Anesthesiology. 1999; 90: 1243-1247. Ref.: https://goo.gl/zVU3wU

8. Laffey JG, Boylan JF, Cheng DC. The systemic inflammatory response to cardiac surgery. Anesthesiology. 2002; 97: 215-252. Ref.: https://goo.gl/qcTDq2

9. Smith P, Treasure T, Newman SP, Joseph P, Ell PJ, et al. Cerebral consequences of cardiopulmonary bypass. Lancet. 1986; 1: 823-825. Ref.: https://goo.gl/RZwu4J

10. Gladstone DJ, Black SE, Hakim AM; Heart and Stroke Foundation of Ontario Centre of Excellence in Stroke Recovery. Toward Wisdom from Failure: Lessons from Neuroprotective Stroke Trials and New Therapeutic Directions. Stroke 2002; 33: 2123 - 2136. Ref.: https://goo.gl/GRZ34D

11. Newman MF, Murkin JM, Roach G, Croughwell ND, White WD, et al. Cerebral physiologic effects of burst suppression doses of propofol during nonpulsatile cardiopulmonary bypass: CNS Subgroup of McSPI. Anesth Analg. 1995; 81: 452-457. Ref.: https://goo.gl/yLm8bV

12. Hollrigel G, Toth K, Soltesz I. Neuroprotection by propofol in acute mechanical injury: role of GABAergic inhibition. J Neurophysiol 1996; 76: 2412-2422. Ref.: https://goo.gl/h8oUmn

13. Bhudia SK, Cosgrove DM, Naugle RI, Rajeswaran J, Buu-Khanh Lam, et al. Magnesium as a neuroprotectant in cardiac surgery: A randomized clinical trial. J Thorac Cardiovasc Surg. 2006; 131 853-861. Ref.: https://goo.gl/g737xX

14. Butterworth J, Hammon JW. Lidocaine for Neuroprotection: More Evidence of Efficacy. Anesth Analg. 2002; 95: 1131-1133. Ref.: https://goo.gl/Y2Nw8F

15. Arrowsmith JE, Harrison MJG, Newman SP, Stygall J, Timberlake N, et al. Neuroprotection of the Brain During Cardiopulmonary Bypass A Randomized Trial of Remacemide During Coronary Artery Bypass in 171 Patients. Stroke. 1998; 29: 2357-2362. Ref.: https://goo.gl/4Dy7D4

16. Ozyurt E, Graham DI, Woodruff GN, Culloch J. Protective effect of the glutamate antagonist MK801 in focal cerebral ischaemia in the cat. J Cereb Blood Flow Metab. 1988; 8: 138-143. Ref.: https://goo.gl/TSzGxt

17. Bruno V, Copani A, Knöpfel T, Kuhn R, Casabona G, et al. Activation of metabotropic glutamate receptors coupled to inositol phospholipid hydrolysis amplifies NMDA-induced neuronal degeneration in cultured cortical cells. Neuropharmacology. 1995; 34: 1089-1098. Ref.: https://goo.gl/ZFdjQ5

18. Burker EJ, Blumenthal JA, Feldman M, Thyrum E, Mahanna E, et al. The Mini Mental State Exam as a predictor of neuropsychological functioning after cardiac surgery. Int J Psychiatry Med 1995; 25 : 263-276. Ref.: https://goo.gl/Ciet9a

19. Lewis MS, Maruff PT, Silbert BS. Examination of the Use of Cognitive Domains in Postoperative Cognitive Dysfunction after Coronary Artery Bypass Graft. Surgery. Ann. Thorac. Surg 2005; 80: 910 - 916. Ref.: https://goo.gl/kUPVNq

20. Weissrock S, Levy F, Balabaud V, Thiranos JC, Dupeyron JP, et al. Interest of the Mini Mental State Examination to detect cognitive defects after cardiac surgery. Ann Fr Anesth Reanim 2005; 24: 1255 1261. Ref.: https://goo.gl/BmesV8 